\title{
TECHNOLOGICAL REMEDY FOR MUSIC PRACTICAL LESSONS AMIDST COVID-19 RESTRICTIONS IN THE DEPARTMENT OF MUSIC EDUCATION, UNIVERSITY OF EDUCATION WINNEBA
}

\author{
Stephen Nyanteh Ayensu', Emmanuel Obed Acquah ${ }^{2}$ and John Francis Annan² \\ ${ }^{1}$ Department of Music Education, University of Education, Winneba \\ ${ }^{2}$ Department of Music Education, University of Education, Winneba
}

Cite this article:

Ayensu S.N., Acquah E.O., Annan J.F. (2021),

Technological Remedy for Music Practical Lessons Amidst Covid-19 Restrictions in the Department of Music Education, University of Education Winneba. British Journal of Contemporary Education 1(1), 84-98. DOI: 10.52589/BJCE-

RHWNFHLW.

\section{Manuscript History}

Received: 21 Oct 2021

Accepted: 9 Nov 2021

Published: 27 Nov 2021

Copyright $\odot 2020$ The Author(s). This is an Open Access article distributed under the terms of Creative Commons AttributionNonCommercial-NoDerivatives 4.0 International (CC BY-NC-ND 4.0), which permits anyone to share, use, reproduce and redistribute in any medium, provided the original author and source are credited.
ABSTRACT: The Department of Music Education, University of Education Winneba (UEW), trains students to acquire the skill of playing some Western instruments such as the keyboard, guitar, winds and orchestral strings. Furthermore, students also receive training in playing Ghanaian traditional instruments such as the atenteben and the various traditional drums of the existing ensembles. This practical teaching also include singing, dancing and ensemble making to allow all students perform their instruments in an ensemble. Unexpectedly, training in these instruments and ensembles was despaired by measures to contain the spread of Covid-19 pandemic. While theory courses in music were conducted via platforms such as Moodle, Google Classroom, the University's Virtual Class (VClass) and Zoom, the exploratory case study design was used to seek technological means to conduct practical lessons which almost came to a halt as a result of its face-to-face teaching nature. Reviewing literature on technologies for teaching and Covid-19, the study which was based on Technological Pedagogical Content Knowledge (T-PACK) model unearthed means to conduct practical lessons. Lecturers, instructors, technicians and students of the Department were interviewed to organize their opinions on how to conduct practical lessons amidst Covid-19 restrictions. The study divulged innovative technological means to situate software programmes and applications such as Zoom, Google Classroom, Moodle, Microsoft Meet, Team Viewer, WhatsApp and Facebook for practical lessons.

KEYWORDS: Covid-19, T-PACK, UEW, Indigenous Drums, Music Education, Atenteben 


\section{INTRODUCTION}

The outbreak of the Coronavirus (Covid-19) pandemic became a surprise situation and smacked all dimensions of global economies including Ghana. This outbreak particularly affected education, especially the Performing Arts oriented courses in the Universities. In March 2020, the World Health Organization (WHO) declared the Covid-19 as a global pandemic with lots of caution to the world about its extremely contagious nature (WHO, 2020). This was after the first cases had been recorded in the Chinese city of Wuhan in December 2019. The disease spread to many countries and Ghana recorded its first two cases on 12th March, 2020. As a result of the outbreak in Ghana and subsequent rising cases, the Ghana government placed a ban on all social gatherings which included funerals, church services, political gatherings, Islamic worships, conferences, beach gatherings, discotheques and cinemas, in order to check the spread of the disease. Following this, schools and colleges were closed and a number of protocols to avoid the spread of the disease were rolled out by the Ministry of Health (MoH) of Ghana. The Ministry of Education (MoE) instructed all Universities, the Vice-Chancellors Ghana (VCG) to device ways and means to end their semesters that were interrupted by the pandemic. The University of Education, Winneba quickly rolled out its Moodle to bring the semester to a logical conclusion and consequently introduced the VClass to begin the following semester. The online teaching favoured most theory courses than the practical courses, relegating music practical instructions in the University to the background. Tutorials in Orchestral Strings, Winds, Keyboard and Piano, Guitar, Traditional drum instructions as well as ensemble making were greatly affected. These uncertainties required a study like this to find creative and innovative means to make the instrumental and ensemble instructions in the Department survive within the context of VClass teaching mode. The paper begins with a theoretical framework and navigates through a review of related literature, methodology, discussion of findings and Conclusions.

\section{THEORETICAL FRAMEWORK}

This study was based on the Technological Pedagogical Content Knowledge (T-PACK) model propounded by Mishra and Koehler (2006). According to Mishra and Koehler (2006), the TPACK framework builds on Shulman's (1987) descriptions of PCK to describe how teachers' understanding of educational technologies and PCK interact with one another to produce effective teaching with technology. Furthermore, Lee Shulman, the $8^{\text {th }}$ president of the Carnegie Foundation for Advancement Teaching introduced the term Pedagogical Content Knowledge in his address to the American Educational Research Association. According to him, T-PACK is "the second kind of content knowledge which goes beyond knowledge of subject matter per se to the dimension of subject matter knowledge for teaching" (Shulman, 1986, p. 9). Upon this foundation, Mishra and Koehler (2006) created the Technological Pedagogical Content Knowledge (T-PACK) model for the effective use of technology in teaching. Mishra and Koehler (2006) described three components of teaching with technology: content, pedagogy, and technology, plus the relationships among and between them. Establishing good teaching with technology on the standards in content, pedagogy and technology, Mishra and Koehler (2006) further stated, "The interactions between and among the three components, playing out differently across diverse contexts, account for the wide variations seen in the extent and quality of educational technology integration"(p.13). The relation between the three components highlighted determines the effectiveness of educational 
technologies. For instance, Schmidst et al. (2009) are of the view that the T-PCK framework acronym was renamed T-PACK (pronounced "tee-pack") to make it easier to remember and to form a more integrated whole for the three kinds of knowledge addressed: technology, pedagogy, and content.

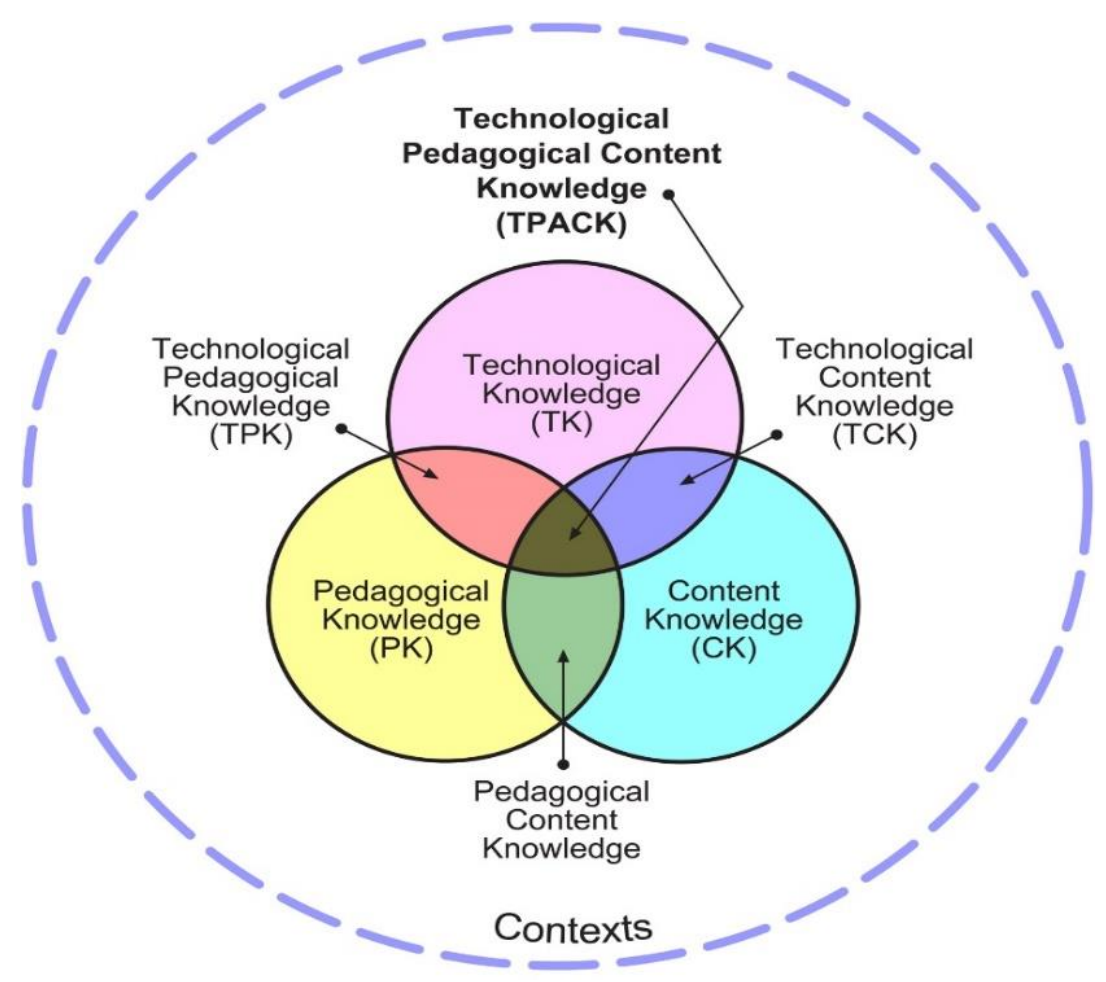

Figure 1. The TPACK framework and its knowledge Mishra \& Koehler (2006)

Describing the Technological Pedagogical Content Knowledge (T-PACK) model, Mishra and Koehler (2006) revealed seven operational principles that govern T-PACK. These principles are formulated based on the three main components in T-PACK and its relationship with the others. At the intersection of these three knowledge types is an intuitive understanding of teaching content with appropriate pedagogical methods and technologies (Schmidst et al. 2009). Appropriating these principles, the study articulated the bases to coordinated contemporary technology such as Zoom, Google Classroom, Google Meet, TeamViewer, Microsoft Team, Youtube, Facebook, Whatsapp, videos and audios with the right pedagogical methods to create content for practical lessons in music on distance bases. Building on the TPACK model, the study explored structures that could be used to conduct practical lessons in the various practical areas of music on distance mode to supplement on-campus lessons. 


\section{The Seven Component of T-PACK}

T-PACK extensively describes seven operative ideologies which reinforce the use of technological systems in teaching, these are Technology knowledge (TK), Content knowledge (CK), Pedagogical Knowledge (PK), Pedagogical content knowledge (PCK), Technological content knowledge (TCK), Technological pedagogical knowledge (TPK), and finally Technological pedagogical content knowledge (TPACK).

\section{Technology Knowledge (TK)}

Technology knowledge refers to the knowledge about various technologies, ranging from lowtech technologies such as pencil and paper to digital technologies such as the Internet, digital video, interactive whiteboards, and software programmes (Schmidst et al. 2009). Possessing profound knowledge in technology enables the teacher to adapt simple and complex technological means for teaching and learning. According to Mishra and Koehler (2006), Technology knowledge (TK) is always in a state of flux-more so than the other two core knowledge domains in the T-PACK framework (pedagogy and content). The teacher needs to be constantly updated in technological systems ranging from the use of pencil and paper to the use of the internet, digital video, interactive whiteboards, and software programmes. Describing Technology Knowledge (TK), Mishra and Koehler (2006) opined that, TK used in the T-PACK framework is close to that of Fluency of Information Technology (FITness), as proposed by the Committee of Information Technology Literacy of the National Research Council (NRC, 1999). Technological Knowledge requires the ability to understand information technology and use it productively. This knowledge enables a teacher to undertake a variety of tasks with information technology and develop different ways of accomplishing a given task. Informed in technological knowledge will enable a teacher or an instructor to use various software programmes and applications to handle practical courses on the distance mode. For instance, knowledge in software programmes like TeamViewer, which can facilitate online connections between various computers in different locations, can be used for educational purposes. Using TeamViewer, a piano instructor can connect to students' piano and guitar applications, piano and guitar learning software packages, conduct video and audio conference with students.

\section{Content knowledge (CK)}

Discussing Content Knowledge, Mishra and Koehler (2006) revealed that, Content knowledge is the knowledge about actual subject matter that is to be learned or taught. Teachers should be conversant with the content they are going to teach and how the nature of knowledge differs from various content areas. The content in piano lessons is different from the content in African ensemble lessons, which involve drumming and dancing. Having Knowledge of the content is essential for teachers. According to Shulman (1986), Content Knowledge would include knowledge of concepts, theories, ideas, organizational frameworks, knowledge of evidence and proof, as well as established practices and approaches toward developing such knowledge. Every field of study has exclusive nature of knowledge, and the teacher or trainer should have a deep understanding of the fundamentals of knowledge in a specific discipline. In the case of practical courses in music, this would imply knowledge of concepts in rhythm, ideas for melody, concepts in fingering, tonguing, bowing, plucking, dance movements and theories in dynamics. 


\section{Pedagogical knowledge (PK)}

Pedagogical Knowledge refers to the methods and processes of teaching and includes knowledge in classroom management, assessment, lesson plan development, and student learning (Schmidst et al. 2009). This involves the teacher's knowledge about the processes, practices and methods of teaching and learning. According to Mishra and Koehler (2006), they encompass, among other things, overall educational purposes, values and aims. This generic form of knowledge applies to understanding how students learn, general classroom management skills, lesson planning and student assessment. Pedagogical Knowledge involves the teachers' knowledge of techniques used in teaching. It also comprises the calibre of students to be taught and how to evaluate their understanding. The ability of the teacher to recognize how students assimilate knowledge and acquire skills is crucial in using the right pedagogical assistance. The ability of instructors or teachers to recognize how various students assimilate African drumming and dance will shape the pedagogical method to employ in teaching African drumming and dancing especially using technological means.

\section{Pedagogical Content Knowledge (PCK)}

Pedagogical Content Knowledge (PCK) refers to the content knowledge that deals with the teaching process (Shulman, 1986). To develop better teaching practices for specific content, pedagogy and content knowledge need to be consistent. The concept of Pedagogical Content Knowledge (PCK) is to transform the method of teaching with content knowledge. According to Shulman (1986), this transformation occurs as the teacher interprets the subject matter, finds multiple ways to represent it and adapts and tailors the instructional materials to alternative conceptions and students' prior knowledge. The subject matter of a traditional dance class needs to be represented with a set of teaching principles that will enable the objectives of the class to be achieved. On the contrary, teaching the songs of the same traditional dance will require different pedagogical principles. The teacher or instructor should be organized in deploying specific teaching methods based on the content to be delivered.

\section{Technological Content Knowledge (TCK)}

According to Schmidst et al. (2009), Technological Content Knowledge refers to the knowledge of how technology can create new representations for specific content. Technological content knowledge recommends that the teacher or instructor's understanding of specific technologies will enable them to modify the way students practice and understand concepts in specific content. Schmidst et al. (2009) revealed that understanding the impact of technology on the practices and knowledge of a given discipline is critical to developing appropriate technological tools for educational purposes. The ability of the teacher to understand technological efficiency in knowledge acquisition in specific subject areas will empower the teacher to use technological tools for teaching. How Music teachers and instructors understand the technological systems will position them to use the right technological methods for practical lessons. Practical lessons in brass, woodwind, guitar, bass guitar, strings can be represented with appropriated technological systems for distance-based practical lessons. The inability of students to have face-to-face interactions with teachers and instructors of practical lessons can be supplemented when the teacher or instructor understands technological systems such as Zoom, Google Meet and TeamViewer. 


\section{Technological Pedagogical Knowledge (TPK)}

Technological Pedagogical Knowledge refers to the knowledge of how various technologies can be used in teaching, and understanding that using technology may change the way teachers teach (Schmidst et al. 2009). Technological Pedagogical Knowledge signifies how specific technologies can be adopted for teaching and learning in different ways. This includes knowing the pedagogical affordances and constraints of a range of technological tools as they relate to disciplinarily and developmentally appropriate pedagogical designs and strategies (Koehler \& Mishra, 2006). Technological Pedagogical Knowledge requires teachers to be abreast and creative with the potentials and limitations of a particular technology and also parallel that technology with pedagogical methods and plans to facilitate teaching and learning. This technological understanding needs to be intensely linked to the content of the discipline in order to reveal the potentials of that technology. There are various software packages that were not designed specifically for teaching but knowing how to use these packages shall enable the teacher to appropriate them for practical lessons in music. This is why according to Koehler and Mishra (2006), teachers need to reject functional fixedness and develop skills to look beyond most common uses for technologies, reconfiguring them for customized pedagogical purposes. Software packages like Zoom, Microsoftware Meet and TeamViewer can be organized to conduct practical lessons in guitar, keyboard and traditional dance. The potency of the teacher's technological and pedagogical knowledge will enable practical lessons to be conducted via technological platforms which were not specifically created for such purpose.

\section{Technological Pedagogical Content Knowledge (TPACK)}

According to Schmidst et al. (2009), Technological Pedagogical Content Knowledge refers to the knowledge required by teachers for integrating technology into their teaching in any content area. The teacher is expected to understand how Content Knowledge, Pedagogical Knowledge and Technological Knowledge interact to provide an accurate representation of content using appropriate pedagogical methods on a technological platform. Distinctive comprehension of these three areas (CK, PK, TK) does not ensure the realization of the vision of T-PACK. TPACK involves effective teaching with technological systems which requires the understanding of how concepts are represented with technological systems and understanding of how pedagogical methods can influence these technological systems for productive teaching of content. Being aware of students' challenges in understanding concepts and how technology can be used to amend these problems is the vision of T-PACK. Moreover, knowledge on how technologies can be used to build on existing knowledge to reinforce understanding of content is the focus of T-PACK. According to Schmidst et al. (2009), the solutions to teaching challenges lie in the ability of a teacher to flexibly navigate the spaces defined by the three elements of content, pedagogy, and technology and the complex interactions among these elements in a specific context. Considering practical lessons in music, the capability of the teacher to remodify face-to-face practical lessons with the necessary technological systems ensuring accurate delivery of unalleviated content with the appropriate pedagogy is the vision of T-PACK. Complying with the T-PACK model, a teacher or an instructor for piano or strings needs to be able to avoid complete discontinuation of practical lessons using the T-PACK model. A piano instructor with the pedagogical skill can use the appropriate technological systems to deliver practical lessons on distance mode without compromising on the content. 


\section{REVIEW OF RELATED LITERATURE}

\section{Technologies for Teaching}

The dispensation of computer and internet technology has influenced facets of professional and educational activities. The use of technological resources is gradually dominating in societies and it has been proven effective for educational reforms. Contemporary technological arsenals such as computers, software, internet, mobile applications and communication devices have expanded the terrain of academic activities. A great number of universities worldwide provide educational packages for students using online Moodles, mobile applications, software, websites, video and audio communication networks. Universities in Ghana and other West African countries also use such packages to provide education to students with convenience and proximity challenges. According to Sun and Chen (2016), the advent of the World-Wide Web (WWW) in 1991 was a powerful catalyst for moving distance education forward and was a milestone in the rapid expansion and growth of online teaching and learning. The importance of educational technologies has persistently ascended with the rise of new technologies and the internet. In light of this, the University of Education Winneba has cherished the use of technological mechanisms to facilitate online teaching especially to students with accessibility and nearness challenges. The University of Education, Winneba, which was established in 1992, has persistently paralleled on-campus tuition with technological systems such as Moodle, educational software, video and audio packages. The University runs distance courses facilitated in all the sixteen regions in Ghana. All these responsibilities propel the university to employ various technological systems to circumspectly organize teaching and learning on genuine configurations. Early adopters of e-learning espoused it benefits and predicted that it would cause a paradigm shift in academia (Buzzetto-More, 2007). Indeed, the presence of technological systems in the University of Education, Winneba have had a tremendous impact on paradigms; however, the act of positioning such technologies to complement practical lessons in music have not been explored. According to Cain (2004), technological developments have brought with them practical changes in the music curriculum as teachers have incorporated new hardware and software into their teaching. Certainly, the introduction of music technology has encouraged the use of technological mechanisms in the study of music. However, how these technologies can be calibrated to enable distance education in music practical courses have not been considered in the Department of Music Education of the University of Education, Winneba. Following the outbreak of the novel Covid-19 pandemic, theory courses have been shielded with technological systems that enable the continuation of lessons upon Covid-19 restrictions. The Department of Music Education, like other Departments in the University teaches practical courses that are geared towards developing students professionally, yet managing practical lessons in Covid-19 restrictions has not been entirely fruitful. Music students are disengaged from practical instructors in keyboard skills, guitar, bass guitar, brass, woodwinds, strings and traditional ensembles. Based on the Technological Pedagogical Content Knowledge (T-PACK) model (Mishra \& Koehler, 2006), this study brings to light, a means of conducting practical lessons in music using technological systems to complement the University's Moodle, which is used for theory courses. 


\section{Ramifications of COVID-19}

According to Bonful et al. (2020), coronavirus disease 2019 (COVID-19) is an infectious disease caused by coronaviruses, specifically, severe acute respiratory syndrome coronavirus 2 (SARS-CoV-2). The outbreak of this novel coronavirus has caused death and other health challenges in more than two hundred countries in the world. Bonful et al. (2020), further indicated that, from the time the disease was first reported in the Wuhan Province in China in December 2019, it has affected more than three million people globally, with over two hundred thousand deaths in 212 countries and territories. The outbreak of this disease has affected various facets of social, economical and educational activities. Ouassou (2020) revealed that the virus that causes COVID-19 is thought to spread mainly from person to person, mainly through respiratory droplets produced when an infected person coughs or sneezes.

\section{METHODOLOGY}

This study was approached with an exploratory design configured with case study since little is known in accessing and measuring information on the effectiveness of using recent technological platforms to conduct practical lessons in music. According to Yin (2003), an exploratory case study is used to explore those situations in which the intervention being evaluated has no clear, single set of outcomes. There may be several outcomes and arguments out of this study as this study serves as a groundbreaking inquiry for further study. According to Teegavarapu, Summers and Mocko (2008), case study can be defined as an empirical research method used to investigate a contemporary phenomenon, focusing on the dynamics of the case, within its real-life context. COVID-19 restrictions prevented face-to-face interactions with students following the directives from the government of Ghana through the University management to reduce the spread of COVID-19 virus. The University online learning platforms had no provision for practical lessons in music therefore conducting practical lessons virtually became impossible. Lecturers, instructors and service persons found it difficult to organize their practical lessons online due to the inability to use appropriate technologies for practical lessons. This fought against the objectives of practical lessons in the Department of Music Education, as most practical lessons in the various instrumental areas and ensemble seized and for that matter regular students' assessment and examinations in practical areas in music could not come on. Considering the case of the Department of Music Education, University of Education Winneba, the study adopted case study design to consider how practical lessons in the Department of Music Education could be conducted amid COVID-19 restrictions where mainstream students were engaged on distance platforms with technological systems. Case study research, through reports of past studies, allows the exploration and understanding of complex issues. It can be considered as a robust research method particularly when a holistic, in-depth investigation is required (Zainal, 2007). To vividly explore how practical lessons in music could be conducted using technological systems amid COVID-19 restrictions, this design was appropriate for the study. Employing this design, sufficient information was gathered based on the context of the situation which enabled the discovery of candid remedy in addressing that educational problem.

Knowing those directly in charge of the various practical lessons and ensembles in the Department of Music Education, purposive sampling was used to select lecturers, instructors, national service persons and technicians for this study. The president of the Association of 
Music Students (AMUS) of the University of Education, Winneba was also purposively selected for this study. In addition, convenient sampling was used to engage students who were still within the university setting to solicit for their views concerning practical lessons on online platforms. Interview was used as a research instrument for this study. Lecturers, instructors, national service persons, students and technicians of the Department were interviewed on the subject matter. Unstructured interview was used to acquire data from the respondents. Although the interview was not structured, it was organized based on practical areas in the Department - Piano/keyboard skills, Voice, African Instruments/Ensembles, Winds and Strings units. All these units have lecturers, instructors and service persons who facilitate the practical lesson. The dynamics in the practical areas informed structural investigation which enabled the possibility to reckon reactions from the respondents.

\section{Piano/Keyboard Skills}

Three lecturers and two instructors from the Piano/Keyboard Skills unit were interviewed on conducting practical lessons in piano/keyboard within the COVID-19 restrictions. They revealed their preparedness to modify their pedagogical methods of teaching keyboard skills using any technological systems provided by the University. An interview with a lecturer in this unit revealed how he was experimenting with TeamViewer to conduct keyboard lesson online. The other two lecturers in an interview revealed how they were using WhatsApp platforms to engage students. Also, the two instructors in this unit revealed how they were using Google Meet in conducting keyboard lessons. Although such schemes were not officially rolled out in the Department. The students interviewed made known their readiness to comply with any initiative instituted by the Department. Five students who were conveniently interviewed described the phenomenon as innovative, however, they also revealed the challenges to be faced by using such schemes.

\section{Voice}

The lecturer in charge of the voice unit revealed how she was already employing WhatsApp groups to engage students in an interview. An instructor who was also engaged in this study through interview described how she was complying with the technological scheme initiated by the head of the Voice unit. Three Voice major students expressed their reception of voice lessons in WhatsApp groups. They were of the view that an interactive system through video conferencing platforms such as Zoom and google meet would have been more preferable. The unit head indicated that plans were far advanced in purchasing Zoom for the Department for such purposes.

\section{Winds}

The unit head disclosed in an interview that he could not do much in terms of practical lessons, however, students called him for assistance relating to the pieces they were learning. The unit head was skeptical about the internet connectivity knowing very well that the majority of technological systems which were likely to be deployed needed internet connectivity. As at the time of the interview, he disclosed that he had not employed any system yet to conduct lessons but he believed that it would be possible to use video conferencing to interact with students. Using a convenience sampling technique, some students were interviewed on how they were expecting their off-campus practical lessons to be rendered. Revealing how they were 
conversant with technological systems like Zoom and Google meet, they expressed their internet connectivity challenges at their off-campus locations.

\section{Strings}

Strings unit in the Department of Music Education includes the violin, viola, cello, double bass, guitar and bass guitar. The head of the unit and the instructors of various instruments in this section expressed how uncomfortable they were as they were worried with the kind of playing skills of their students when they came back to campus after the COVID-19 restrictions, probably, with rusty playing techniques. According to the unit facilitators, string instruments demand consistent practicing with strict adherence to fingering, bowing and plucking techniques and major assistance from the instructors. According to the unit supervisor, except for few students who will practice on their own, the majority of the students need to be supervised to rehearse. String students who participated in the study were interviewed on how practical lessons could continue within COVID-19 restrictions. According to the respondents, moving through the technological way of teaching would be more appropriate to unlock the difficulties. Although students were looking forward to interactive sessions with their instructors via technological platforms but they could not suggest how to make this interaction possible. The unit head revealed how he was planning to use Zoom in conducting practical lessons, although, he was pessimistic about the effectiveness of such schemes.

\section{African Musical instruments}

The African Instrument Unit head found the impossibility in conducting dance class within the COVID-19 restrictions. She managed to upload previously recorded videos of traditional dance and drumming on the University Moodle for the students to watch and practice but she was of the view that the videos uploaded were performance videos and not teaching videos. According to her, dance and drumming videos for teaching should be created with the necessary pedagogical methods to achieve the objective of the lessons. A lecturer, an instructor and service person in the same unit revealed how they prepared dance videos on some ensembles on some of the Ghanaian dances for students through Google classroom, however, students' reception to these documents could not be quantified and its effectiveness could not be discussed. For the atenteben and the gyile, the unit facilitators had not considered any remedy yet. Students interviewed during the study revealed that they would be glad if lessons in this regard were designed using technological systems like Zoom, Google Meet and WhatsApp platforms.

\section{Technician}

The study proceeded with a comprehensive interaction with the technician of the Department who is a graduate in Music as well. The technician was in charge of all the technical challenges in the Department. His duties includes setting up for the Department's concert, taking charge of the Departments recording studio, assisting technically with practical and theory courses, taking care of the Departments ICT laboratory and teaching Music Technology. Being the technician for the Department, the study inquired from him various technological structures that could be put in place to enable practical lessons to continue, amidst Covid-19 ramifications. Starting from keyboard skills, the technician opted for the use of video conferencing platforms previously revealed by the facilitators of keyboard skills and also recommended the use of computer connectivity software programmes like TeamViewer and 
AnyDesk. He explicitly described how these packages could be used for distant-based practical lessons. He described the necessary items to consider in order to establish a connection between the student's piano and the teacher's piano. According to the technician, the piano teacher could have a video conference with his students behind their piano. He continued to divulge that the teacher could choose to give personal or general instructions to students by using the mute and unmute microphone options on Zoom. He further disclosed that the teacher could also decide on the student to listen to at every instance with the mute option. The technician deemed the use of Zoom, TeamViewer and Anydesk as reliable platforms for the continuation of practical lessons in keyboard skills amid COVID-19 restrictions. He revealed that although Zoom is not created for practical lessons, in as much as it establishes a consistent connection with student, it proves that it could be used as a platform for practical lessons in keyboard skills. With computer connectivity software like TeamViewer and AnyDesk, the technician disclosed that students could be asked to download virtual piano on their personal computer and use a MIDI cable to connect their hardware electronic keyboards to the computer. Employing Team Viewer or AnyDesk, the piano teacher could connect to the students' computer and engage the student in a practical lesson. The technician revealed that using this, the teacher would have the privilege to check students fingering, articulations, precision of notes and the use of sustain pedals as the virtual piano would give details of all these qualities. He further revealed that challenges in sections performed by the students could easily be recognized by the software indications and students could also be given specific task in piano lessons by using the software. He mentioned software programmes like Flowkeys, Skoove, Pianoforall and Piano Marvel,

According to the technician, other practical units in the department could also use the Zoom platform for practical lessons. What the technician deemed challenging was practical lessons in traditional drumming and the gyile. According to the technician, students possess keyboards, atenteben, trumpets and other practical instruments but instructions in drumming and playing of gyile were a problem since it was impossible for individual students to acquire those instruments in readiness for online lessons. He added, for dance lessons, teachers could use Zoom and Google Meet but the teacher's setup should involve the percussions. The technician was aware of the internet challenges students might face and therefore he recommended that interactive conference on Zoom and other video conferencing platforms should be recorded and uploaded to the University's Moodle for students who could not connect in real-time to access later after the session.

Finally, he revealed that internet technology has led to the emergence of various online video platforms where instructors could conduct live practical lessons as well as upload videos of practical lessons for students. He recommended the use of Youtube and Facebook for such an initiative. According to the technician, the world is gradually developing and the inability for teachers to take advantage of the current technological developments would make teachers and students unyielding.

\section{General Students' Concerns}

Focus Group Discussion (FGD) carried out among the student participants, revealed that one of the major challenges they may face was accessibility to and reliability of the internet. Besides, they revealed that the cost of connecting to practical lessons via platforms like Zoom, and Google meet involves budgets which might not be able to affordable. They, therefore, recommended a free package of internet data for students to be able to connect to such 
platforms for video interactive lessons in practical areas of study. Students were also of the view that apart from their location which at times affects connectivity, internet provided by the various mobile communication networks was at times not reliable. Being aware of these challenges, students were ready to use in practical lessons via platforms like Zoom and Google meet.

\section{DISCUSSION OF FINDINGS}

This study sought to reveal ways of conducting practical lessons in music amidst COVID-19 restrictions. Lecturers, instructors, national service persons students as well as students of the Department of Music Education, University of Education, Winneba were engaged to quantify their opinions on means for conducting practical lessons in music amidst the COVID-19 restrictions. Although the interview was unstructured and the effectiveness of the mechanisms revealed by the respondents have not been vividly measured. Thus, members of the various practical units came up with innovative means to conduct practical lessons in music.

It was discovered in the keyboard unit that students are already coping with technological means prescribed by their lecturers and instructors. Stakeholders in this unit were very determined to explore any technological schemes to conduct practical lessons in keyboard with recent technologies. One lecturer who was already experimenting with TeamViewer software programme disclosed that effective exploration of technology in education results innovations that can solve contemporary educational problems. According to this lecturer Covid-19 has brought the opportunity to restructure educational priorities with technological concepts. Explaining his experiment with TeamViewer, the teacher and the student will use an electronic keyboard which will be linked to a computer with a piano software programme that responds to MIDI (Musical Instrument Digital Interface) communication. TeamViewer will then establish a communication between the student's computer and the lecturer's computer. When this connection is established, the teacher will be able to witness the students fingering, position and dynamics. Also the lecturer could demonstrate on his piano for the student to witness on his or her computer. TeamViewer for practical lessons in keyboard was seen to be very appropriate. Google Meet was also found to be good. Once, there is internet connectivity practical lessons could be done. These platforms could be supplemented with recorded videos.

WhatsApp platform was found to be good for Voice tutorials. Voice instructors who used this platform moderated the platforms by instructing students to perform and record their voice pieces onto the platform. Issues with performance of individual students could easily be addressed. Students' submission to the WhatsApp platform was asynchronously organized, however, attending to individual performance and coaching was synchronously handled. This system prevented the regular cue of the instructor in the face-to-face mode and disallowed instant corrections and coaching. This is because students had to wait for feedbacks from lecturers and instructors for days before being attended to. WhatsApp video calls for voice tutorials for synchronous practical lessons could have been appropriate to deal with the issue.

Regular phone call served as a channel for instructions in Winds instructional deliveries. Students who were engaged this way affirmed the necessity to include individual video interaction with the lecturers. Instructions at this unit were very comfortable with face-to-face interactions. This is because teaching the instruments in the units required face-to-face 
interaction to consider instrument position, finger position and bowing techniques, however, the asynchronous interactions on WhatsApp platform could have been helpful. Other intelligent students could also have been provided with the necessary instructions through technological means to complement their efforts to learn on their own. Although the students were doing self-teaching with complementary instructions from lecturers and instructors, they were still expected to go through comprehensive synchronous practical lessons with contemporary technologies.

It was very worrying to adapt to distant mode for the teaching of African instruments, which involved more of drumming, atenteben playing, gyile playing and ensemble making. Songs were taught asynchronously using the University's online teaching Moodle, however, instruments and dance movements required synchronous engagement. The instructor in the African instruments had this to say:

\section{I tried using Zoom for a dance and drumming class but the video latency made cooperation difficult.}

The above statement confirms what Sever (2021) indicated in his studies on online teaching. Another lecturer in the unit revealed that teaching African drum online was not possible since the students do not have personal African drum instruments. The unit therefore uploaded recorded video of dance movement and songs on the university online learning platforms and google class for students. She commented and said:

\section{Drum lessons were not possible but the students respond to the prerecorded videos for dance movements and songs.}

Contrary to this, discussion with the students showed that they had videos on dance movement and songs posted online for their studies, they really required the assistance of the lecturer to breakdown dance movement and songs for easy assimilation. According to them, the uploaded videos were mostly videos from African dance performance, thus, it was difficult to learn the songs as well as the dance movements on their own. Moreover, the teaching of drum pattern was totally relegated because students did not have African drums. In this case, they are marginalized to acquire the skill in their own cultural education (Hess, 2018).

The study further discovered that practical examinations in practical areas like keyboard skills and voice were already conducted using WhatsApp platform where students could record their performance and send to the instructor. However, the lecturers and instructors in such units revealed that it was difficult to use students' submissions as bases for assessment. Teachers often needed to assess whether submitted programmes conformed to given interface or structural requirements as postulated by Ala-Mutka (2005). By its nature, instructors found it difficult to find an assessment design for online practical works. The other units wanted to conduct practical examination but there was no mechanism they could put in place. Various technological mechanisms were explored for the majority of practical lessons in the Department but examination in this area was challenging. Apart from the keyboard and the voice units which tried using WhatsApp platforms for examination in practical lesson, the other units did not have any system for examination. Except for Google Classroom, the various technological mechanisms for teaching amid the COVID-19 pandemic discovered in this study were not created for teaching but it was realized that lecturers, instructors and teaching assistants in the Department were employing Technological Pedagogical Content Knowledge 
(T-PACK) in this regard to hold the fort in practical lessons in the Department of Music Education University of Education, Winneba.

\section{CONCLUSIONS}

Effectual employment of Technological Pedagogical Content Knowledge (T-PACK) (Mishra \& Koehler, 2006) amid COVID-19 restrictions advances the appropriation of technological mechanisms to render uncompromised practical lessons in music with suitable pedagogical systems. Apart from internet connectivity challenges, the available technological provisions can be appropriated for practical lessons for distant mode of giving instructions. All things being equal, practical lessons in keyboard, strings, winds and voice in the Department of Music Education University of Education, Winneba could be conducted with technological platforms such as Zoom, Google Classroom, Moodle, Microsoft Meet, TeamViewer, WhatsApp and Facebook. Except for the African unit which will require technological infrastructure due to the nature of the lessons and the items involved, it is possible to use contemporary technologies for practical lessons in the other four (4) units in the Department. Traditional drumming and xylophone lessons will require students to have such traditional instruments, however, other practical aspects in the African unit such as the atenteben, traditional dance and traditional singing lessons could be conducted with contemporary technological structures discovered in this study, provided internet connectivity is reliable and online video conference is in real-time.

Also, teachers of practical lessons in music can upload videos of the lesson on Youtube, Facebook and other video streaming platforms for the students to interrelate with. Just as it was discovered, students' response and feedback could be sent through WhatsApp platform. Complying with this, monitoring and assessment of the students could be initiated and the students as well could have an interaction with their teacher.

\section{REFERENCE}

Ala-Mutka, K. M. (2005). A survey of automated assessment approaches for programming assignments. Computer science education, 15(2), 83-102.

Bonful, H. A., Addo-Lartey, A., Aheto, J. M., Ganle, J. K., Sarfo, B., \& Aryeetey, R. (2020). Limiting spread of COVID-19 in Ghana: compliance audit of selected transportation stations in the Greater Accra region of Ghana. PloS one, 15(9), e 0238971.

Buzzetto-More, N. A. (2007). Principles of Effective Online Teaching, Santa Rosa, Califonia: Informing Science Press

Cain, T. (2004). Theory, technology and the music curriculum. British Journal of Music Education, 21(2), 215-221.

Hess, J. (2018). Musicking marginalization: Periphractic practices in music education. In The Palgrave handbook of race and the arts in education (pp. 325-346). Palgrave Macmillan, Cham.

Mishra, P., \& Koehler, J. (2006). Technological Pedagogical Content Knowledge: A Framework Teacher Knowledge. Teachers College Record, 108(6), 1017-1054.

Ouassou, H., Kharchoufa, L., Bouhrim, M., Daoudi, N. E., Imtara, H., Bencheikh, N., ELbouzidi, A., \& Bnouham, M. (2020). The Pathogenesis of Coronavirus Disease 2019 (COVID-19): Evaluation and Prevention. Journal of Immunology Research, 1357983. 
Schmidt, A., Baran, E., Thompson, D., Mishra, P., Koehler, J., \& Shin, S. (2009). Technological pedagogical content knowledge (TPACK): The development and validation of an assessment instrument for pre-service teachers. Journal of Research on Technology in Education, 42, 123-150.

Sever, G. (2021). Opinions of Teachers on the Implementation of the Orff-Schulwerk Approach in Online Lessons. International Online Journal of Educational Sciences, 13(4).

Shulman, L. (1987). Knowledge and teaching. Harvard Educational Review, 57(1), 1-21.

Shulman, S. (1986). Those who understand: Knowledge growth in teaching. Educational Researcher, 15 (2), 4-14.

Sun, A., \& Chen, X. (2016). Online Education and Its Effective Practice: A Research Review. Journal of Information Technology Education: Research, 15, 157-190.

Teegavarapu, S., Summers, D., Mocko, M., \& ASME (2008). International Design Engineering Technical Conferences and Computers and Information in Engineering Conference, IDETC/CIE. Case study method for design research: A justification. Proceedings of the Asme Design Engineering Technical Conference, 4, 495-503.

World Health Organization. (2020). Responding to community spread of COVID-19: interim guidance. World Health Organization.

Yin, K. (2003). Applications of case study research. SAGE.

Zainal, Z. (2007). Case study as a research method. Jurnal Kemanusiaan, 9, 1-6.

Zainuddin, Z., Perera, C. J., Haruna, H., \& Habiburrahim, H. (2020). Literacy in the new norm: stay-home game plan for parents. Information and Learning Sciences, 121(7/8), 645-653. 